\title{
High Eg5 expression predicts poor prognosis in breast cancer
}

\author{
Qin Jin', Fang Huang ${ }^{1}$, Xudong Wang ${ }^{2}$, Huijun Zhu ${ }^{1}$, Yun Xian ${ }^{3}$, Jieying Li ${ }^{1}$, Shu \\ Zhang ${ }^{1}$ and Qichao $\mathbf{~ N i}^{4}$ \\ ${ }^{1}$ Department of Pathlogy, Affiliated Hospital of Nantong University, Nantong 226001, Jiangsu, China \\ ${ }^{2}$ Surgical Comprehensive Laboratory, Affiliated Hospital of Nantong University, Nantong 226001, Jiangsu, China \\ ${ }^{3}$ Health Insurance Office, Nantong University, Nantong 226001, Jiangsu, China \\ ${ }^{4}$ Department of General Surgery, Affiliated Hospital of Nantong University, Nantong 226001, Jiangsu, China \\ Correspondence to: Qichao Ni, email: nqcuser@163.com
}

Keywords: Eg5, BC, prognosis

Received: January 25, $2017 \quad$ Accepted: April 12, $2017 \quad$ Published: July 10, 2017

Copyright: Jin et al. This is an open-access article distributed under the terms of the Creative Commons Attribution License 3.0 (CC BY 3.0), which permits unrestricted use, distribution, and reproduction in any medium, provided the original author and source are credited.

\section{ABSTRACT}

Eg5 is a motor protein belonging to the kinesin-5 family and has been suggested to exert important function in tumors. In this study, we determined the mRNA and protein expression levels of Eg5 in cancerous and non-cancerous breast tissue by quantitative real-time polymerase chain reaction (qRT-PCR) and tissue microarray immunohistochemistry analysis (TMA-IHC) respectively. The results of 20 freshfrozen BC samples demonstrated that Eg5 mRNA levels were significantly higher in BC tissues compared with corresponding non-cancerous tissue $(p=0.0009)$. TMAIHC analysis in $127 \mathrm{BC}$ tissues revealed that Eg5 expression obviously correlated with clinicopathologial parameters, including tumor grade $(p=0.004)$, ER status $(p=0.030)$, Ki67 status $(p=0.005)$, molecular classification $(p=0.026)$, N stage $(p=0.015)$, and TNM stage $(p=0.001)$. Kaplan-Meier survival curve indicated that high Eg5 expression $(p=0.012)$, Ki67 status $(p=0.014)$ and TNM stage $(p=0.026)$ were independent factors to predict poor prognosis for patients with breast cancer. Our data suggest that Eg5 is not only overexpressed in BC, it may be also served as a potential prognostic marker.

\section{INTRODUCTION}

Breast cancer $(\mathrm{BC})$ is one of the most common types of cancers among women; it affects over 1.3 million new patients and causes nearly 0.5 million deaths each year [1]. In China, the incidence of $\mathrm{BC}$ has increased approximately $30 \%$, and the $\mathrm{BC}$ related mortality has doubled over the past 30 years [2-3]. BC is usually classified into several types on the basis of molecular signatures, clinicopathological characteristics, and treatment responses [4]. Despite remarkable advances in the diagnosis and therapy, the outcome of $\mathrm{BC}$ remains unsatisfactory [5-6]. A large number of BC criteria are routinely and widely acknowledged in the clinical field, including estrogen receptor (ER), progesterone receptor (PR), human epidermal growth factor receptor 2 (Her2),
Ki67 proliferative index, TNM stage, tumor grade, metastatic status and molecular classification have been suggested for prognosis [7]. Thus, novel biomarkers are needed to optimize the treatment strategy, evaluate the therapeutic effectiveness, and predict the clinical outcomes of $\mathrm{BC}$.

Eg5, also known as kinesin-5, KSP, or KIF11, is a microtubule-dependent motor protein encoded by KIF11 gene located on human chromosome 10. It plays an essential role in bipolar spindle formation and maintenance in early prometaphase [8-9]. Eg5 is composed of three domains: a motor domain at the N-terminus, a coil stalk domain in the middle, and a tail domain at the $\mathrm{C}$-terminus, and the N-terminus motor domain works with the C-terminus tail domain to form a homotetrameric structure [10]. Correct mitosis is the basis of cell proliferation. The 
correct formation of spindle is the premise for mitosis. $\mathrm{Eg} 5$ regulates spindle formation mainly by the following two mechanisms: (1) KSP reverse the alignment of the anti parallel array of microtubules; (2) by connecting two microtubules in the same direction and moving to their ends, KSP binds with microtubule, which promotes spindle formation [11]. MEg5 of the central microtubules move transient away to the spindle poles. On the contrary, The point-like mEg5 of the astral microtubules moves transient to the microtubule negative in the early stage of mitosis. But in the later period, it moves to the positive electrode. This is the main reason for the polarity accumulation and redistribution of $\mathrm{Eg} 5$ in the early stage of mitosis. So that the understanding the role of Eg5 in mitosis [12]. Usually, Eg5 expression in $\mathrm{CD}^{+} 4^{+}$cell, testis, cardiac muscle cell and some other human normal proliferation tissues. However, the expression level was significantly lower than that in malignant tissues. Studies have evaluated the Eg5 expression and its correlation with clinicopathological characteristics in various malignant tumors. For example, activation of Eg5 expression contributes to the onste of B-cell leukemia [13], Eg5 overexpression has been reported in solid tumors such as lung cancer [14], renal cell carcinoma [15], Metastatic castrateresistant prostate cancer(mCRPC) [16], non-muscle invasive bladder urothelial carcinoma [17], laryngeal squamous cell carcinoma [18], high grade astrocytic neoplasm [19]; in addition, five human pancreatic cancer cell lines (PANC1, EPP85, BxPC3, CFPAC1 and AsPAC1) [20] and ER-positive human breast cancer MCF-7 cell line [21] were also observed higher Eg5 expression, and the inhibition of Eg5 expression blocks cell cycle and inhibits cell proliferation [22-23]. Moreover, transgenic mice over-expressing Eg5 exhibit a high tendency to develop several types of malignancies [24]. These results indicate that $\mathrm{Eg} 5$ has a significant carcinogenic effect; in addition, Eg5 may be used as a novel biomarker of cancer therapy. Nevertheless, the relationship between Eg5 expression and the clinicopathological significance of $\mathrm{BC}$ has not been investigated.

In this retrospective study, our goal was to determine Eg5 expression between $\mathrm{BC}$ tissues and corresponding non-cancerous tissues, and to determine whether $\mathrm{Eg} 5$ could be used as a prognostic marker for BC patients. The mRNA level of Eg5 was detected using quantitative real-time polymerase chain reaction (qRT-PCR) analysis while the protein expression of Eg5 was measured by immunohistochemistry (IHC) analysis. In addition, the relationship between Eg5 expression and significant clinicopathological parameters of BC was evaluated.

\section{RESULTS}

\section{Eg5 mRNA expression in BC patients by qRT- PCR test}

The expression of Eg5 mRNA was analyzed by qRT-PCR in BC tissue samples as well as in corresponding non-cancerous tissue samples obtained from $20 \mathrm{BC}$ patients. Eg5 transcript levels were significantly higher in $\mathrm{BC}$ tissues compared with corresponding non-cancerous tissues $(0.8145 \pm 0.1153$ vs $0.3660 \pm 0.0469,2.23$-fold, $t$ $=3.603, p=0.0009$. Wilcoxon signed-rank nonparametric test) (Figure 1).

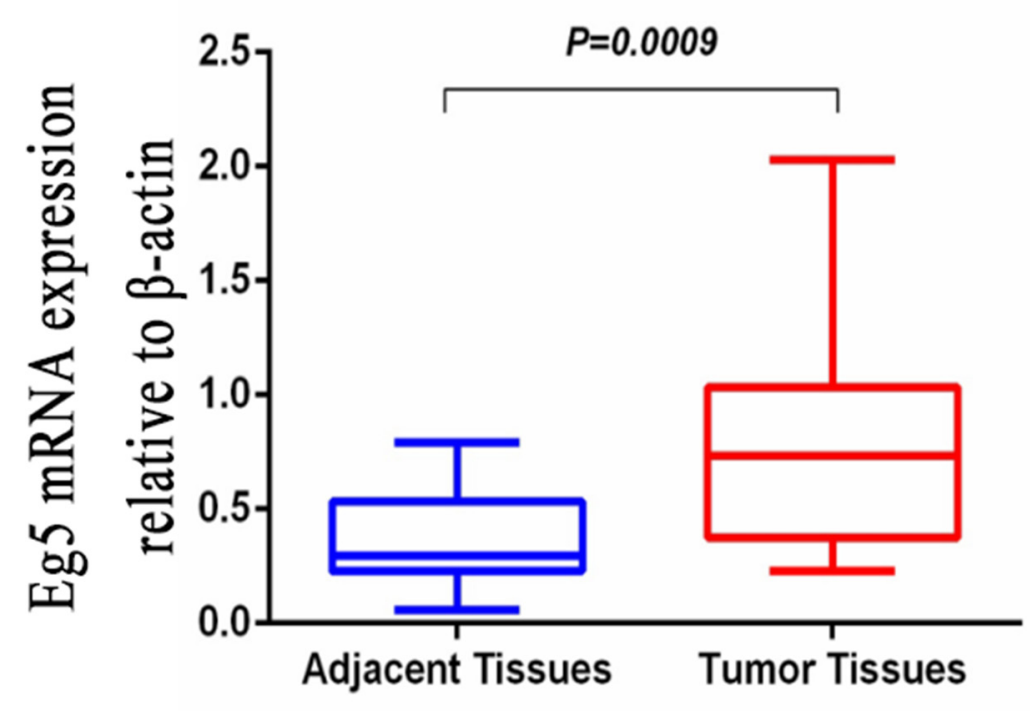

Figure 1: Quantitative real-time polymerase chain reaction (qRT-PCR) was employed to detect Eg5 mRNA expression levels in BC tissues and compared with corresponding non-cancerous tissues. When normalized to $\beta$-actin mRNA levels, the Eg5 mRNA level in BC tissue $(0.8145 \pm 0.1153)$ is significantly higher than that in corresponding non-cancerous tissue $(0.3660 \pm 0.0469)$. 


\section{Expression of Eg5 protein in $\mathrm{BC}$ by IHC test}

To determin the protein expression of Eg5, TMAimmunohistochemistry analysis was performed. As shown in Figure 2, $\mathrm{Eg} 5$ was detected primarily in the cytoplasm of BC cells. High Eg5 expression was detected in 57.5\% $(73 / 127)$ of BC samples, significantly higher $(\chi 2=28.722$, $p<0.001)$ than in $24.4 \%(31 / 127)$ of non-cancerous samples.

\section{Relationship between Eg5 protein expression and clinicopathological attributes of $\mathrm{BC}$}

Subsequently, the relationship between Eg5 protein levels and clinicopathological attributes of $\mathrm{BC}$ patients was investigated (Table 1). High expression of Eg5 was significantly associated with tumor grade $(p=0.004)$, ER status $(p=0.030)$, Ki67 status ( $p=0.005)$, molecular classification $(p=0.026), \mathrm{N}$ stage $(p=0.015)$ and TNM stage $(p=0.001)$. However, Eg5 protein expression was not significantly associate with age, tumor size, PR status, and Her2 status (Table 1).

\section{High Eg5 protein expression predict poor prognosis of $\mathrm{BC}$ patients}

Univariate analysis was used to evaluated $\mathrm{Eg} 5$ protein expression and other clinicopathologic factors on prognosis of $\mathrm{BC}$. High level of $\mathrm{Eg} 5$ protein expression
(HR 1.908; $p=0.003)$, Her2 status (HR 1.705; $p=0.014$ ), Ki67 statue (HR 2.473; $p<0.001)$ and TNM stage (HR 2.306; $p=0.001)$ were significant associated with poor overall survival (Table 2). These prognostic factors were further evaluated by multivariate Cox proportional hazards regression model analysis. High Eg5 expression (HR $1.724 p=0.012$ ), Ki67 status (HR 1.837; $p=0.014$ ) and TNM stage (HR 1.676; $p=0.026$ ) were all independent prognostic markers of poor 5-year overall survival (Table 2). Using the Kaplan-Meier analysis, which is used to assess the survival of $\mathrm{BC}$ patients. $\mathrm{BC}$ patients with high expression of $\mathrm{Eg} 5$ protein had significantly shorter overall survival $(\mathrm{P}=0.002)$ compared with those with low or no Eg5 expression (Figure 3A), and patients with a high Ki67 expression had a poorer overall survival $(\mathrm{P}<0.001)$ than patients with Ki67-low tumors (Figure 3B), patients in TNM stage III had a lower overall survival $(\mathrm{P}=0.001)$ than patients in TNM stageI-II (Figure 3C).

\section{DISCUSSION}

We know Eg5 mainly related to chromosome localization, centrosome separation and the formation and separation of bipolar spindle. The increasing high expression of $\mathrm{Eg} 5$ disturbs the normal assembly of the spindle and the balance of power associated with its function, which eventually leads to the loss of spindle, genomic instability and tumor. In this study,

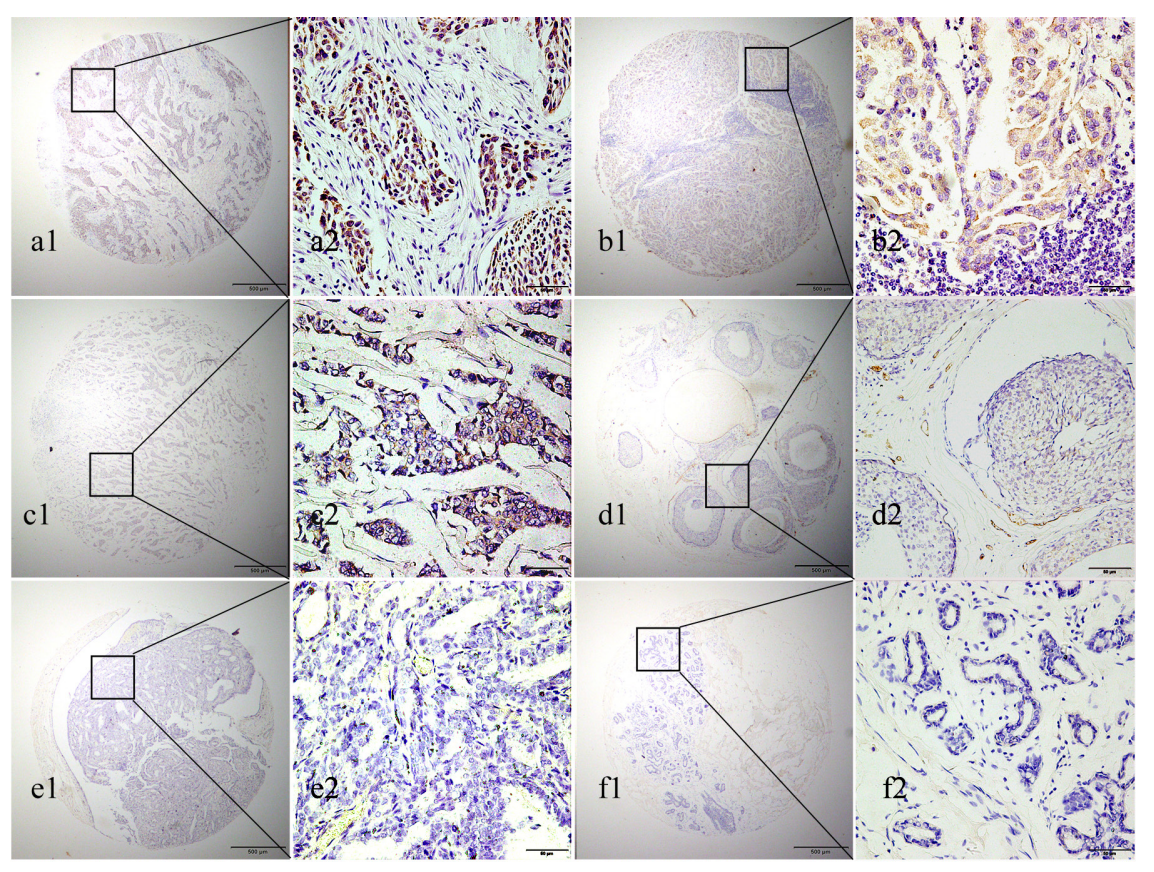

Figure 2: Representative images of Eg5 protein expression in $\mathrm{BC}$ and corresponding non-cancerous tissues with tissue microarray (TMA). (a1, b1, a2 and b2) High IHC staining of Eg5 in the cytoplasm of invasive breast cancer cells. (c1 and c2) Low IHC staining of Eg5 in the cytoplasm of invasive breast cancer cells. (d1 and d2) No IHC staining of Eg5 in the invasive ductal breast cancer cells. (e1 and e2) No IHC staining of Eg5 in the breast ductal papilloma cells. (f1 and f2) No IHC staining of Eg5 in the breast adenosis cells. Original magnification $\times 40$ in (a1, b1, c1, d1, e1, f1); $\times 400$ in (a2, b2, c2, d2, e2, f2). 
Table 1: Association of Eg5 expression with clinical characteristics and selected biological markers of BC

\begin{tabular}{|c|c|c|c|c|c|}
\hline \multirow{2}{*}{ Characteristic } & \multirow{2}{*}{$\mathbf{n}$} & \multicolumn{2}{|c|}{ Eg5 expression(\%) } & \multirow{2}{*}{$X^{2}$} & \multirow{2}{*}{$\mathbf{P}$} \\
\hline & & Low or no & High & & \\
\hline Age (years) & & & & 0.688 & 0.749 \\
\hline$\leq 40$ & 9 & $4(44.4)$ & $5(55.6)$ & & \\
\hline $40-60$ & 76 & $30(39.5)$ & $46(60.5)$ & & \\
\hline$\geq 60$ & 42 & $20(47.6)$ & $22(52.4)$ & & \\
\hline Tumor size (cm) & & & & 1.760 & 0.185 \\
\hline$\leq 2 \mathrm{~cm}$ & 57 & $21(36.8)$ & $36(63.2)$ & & \\
\hline$>2 \mathrm{~cm}$ & 70 & $34(48.6)$ & $36(51.4)$ & & \\
\hline Tumor grade & & & & 8.345 & $0.004 *$ \\
\hline I-II & 78 & $41(52.6)$ & $37(47.4)$ & & \\
\hline III & 49 & $13(26.5)$ & $36(73.5)$ & & \\
\hline ER & & & & 4.701 & $0.030 *$ \\
\hline Negative & 43 & $24(55.8)$ & $19(44.2)$ & & \\
\hline Positive & 84 & $30(35.7)$ & $54(64.3)$ & & \\
\hline PR & & & & 0.747 & 0.387 \\
\hline Negative & 72 & $33(45.8)$ & $39(54.2)$ & & \\
\hline Positive & 55 & $21(38.2)$ & $34(61.8)$ & & \\
\hline Her2 & & & & 0.181 & 0.670 \\
\hline Negative & 82 & $36(43.9)$ & $46(56.1)$ & & \\
\hline Positive & 45 & $18(40.0)$ & $27(60.0)$ & & \\
\hline Ki67 & & & & 7.850 & $0.005 *$ \\
\hline Low & 57 & $32(56.1)$ & $25(43.9)$ & & \\
\hline High & 70 & $22(31.4)$ & $48(68.6)$ & & \\
\hline $\begin{array}{l}\text { Molecular } \\
\text { classification }\end{array}$ & & & & 9.280 & $0.026 *$ \\
\hline Luminal A & 46 & $20(43.5)$ & $26(56.5)$ & & \\
\hline Luminal B & 38 & $10(26.3)$ & $28(73.7)$ & & \\
\hline $\begin{array}{l}\text { Her2- } \\
\text { overexpression }\end{array}$ & 29 & $14(48.3)$ & $15(51.7)$ & & \\
\hline TNBC & 14 & $10(71.4)$ & $4(28.6)$ & & \\
\hline N stage & & & & 5.952 & $0.015 *$ \\
\hline No & 48 & $27(56.2)$ & $21(43.8)$ & & \\
\hline $\mathrm{N} 1+2+3$ & 79 & $27(34.2)$ & $52(65.8)$ & & \\
\hline TNM stage & & & & 11.153 & 0.001 * \\
\hline Stage I-II & 88 & $46(52.3)$ & $42(47.7)$ & & \\
\hline Stage III & 39 & $8(20.5)$ & $31(79.5)$ & & \\
\hline
\end{tabular}


Table 2: Univariate and multivariate analysis of prognostic factors in BC for 5-year overall survival

\begin{tabular}{|c|c|c|c|c|c|c|c|}
\hline & \multirow{2}{*}{ Years } & \multicolumn{3}{|c|}{ Univariate analysis } & \multicolumn{3}{|c|}{ Multivariate analysis } \\
\hline & & HR & $p$ & $95 \% \mathrm{CI}$ & HR & $p$ & $95 \% \mathrm{CI}$ \\
\hline \multicolumn{8}{|l|}{ Expression of Eg5 } \\
\hline High vs low or no expression & 5 & 1.908 & $0.003 *$ & $1.238-2.943$ & 1.724 & $0.012 *$ & $1.028-2.635$ \\
\hline \multicolumn{8}{|l|}{ Age (years) } \\
\hline$\leq 40$ vs $40-60$ versus $\geq 60$ & 5 & 1.194 & 0.342 & $0.828-1.722$ & & & \\
\hline \multicolumn{8}{|l|}{ Tumor grade } \\
\hline I- II vs III & 5 & 1.208 & 0.378 & $0.793-1.840$ & & & \\
\hline \multicolumn{8}{|l|}{ Tumor size (cm) } \\
\hline$\leq 2 \mathrm{~cm} \mathrm{vs}>2 \mathrm{~cm}$ & 5 & 1.093 & 0.675 & $0.720-1.661$ & & & \\
\hline \multicolumn{8}{|l|}{ Expression of ER } \\
\hline Negative vs Positive & 5 & 0.768 & 0.225 & $0.504-1.171$ & & & \\
\hline \multicolumn{8}{|l|}{ Expression of PR } \\
\hline Negative vs Positive & 5 & 0.696 & 0.104 & $0.450-1.078$ & & & \\
\hline \multicolumn{8}{|l|}{ Expression of Her2 } \\
\hline Negative vs Positive & 5 & 1.705 & $0.014 *$ & $1.116-2.605$ & & & \\
\hline \multicolumn{8}{|l|}{ Expression of ki67 } \\
\hline Low vs High & 5 & 2.473 & $<0.001 *$ & $1.580-3.869$ & 1.837 & $0.014 *$ & $1.128-2.991$ \\
\hline \multicolumn{8}{|l|}{ Molecular classification } \\
\hline $\begin{array}{l}\text { Luminal A vs Luminal B vs } \\
\text { Her2-overexpression vs TNBC }\end{array}$ & 5 & 1.184 & 0.073 & $0.985-1.423$ & & & \\
\hline \multicolumn{8}{|l|}{ N stage } \\
\hline $\mathrm{N} 0$ vs $\mathrm{N} 1+2+3$ & 5 & 1.048 & 0.831 & $0.684-1.604$ & & & \\
\hline \multicolumn{8}{|l|}{ TNM Stage } \\
\hline Stage I- II vs Stage III & 5 & 2.036 & $0.001 *$ & $1.502-3.539$ & 1.676 & $0.026 *$ & $1.063-2.642$ \\
\hline
\end{tabular}

$* p<0.05$
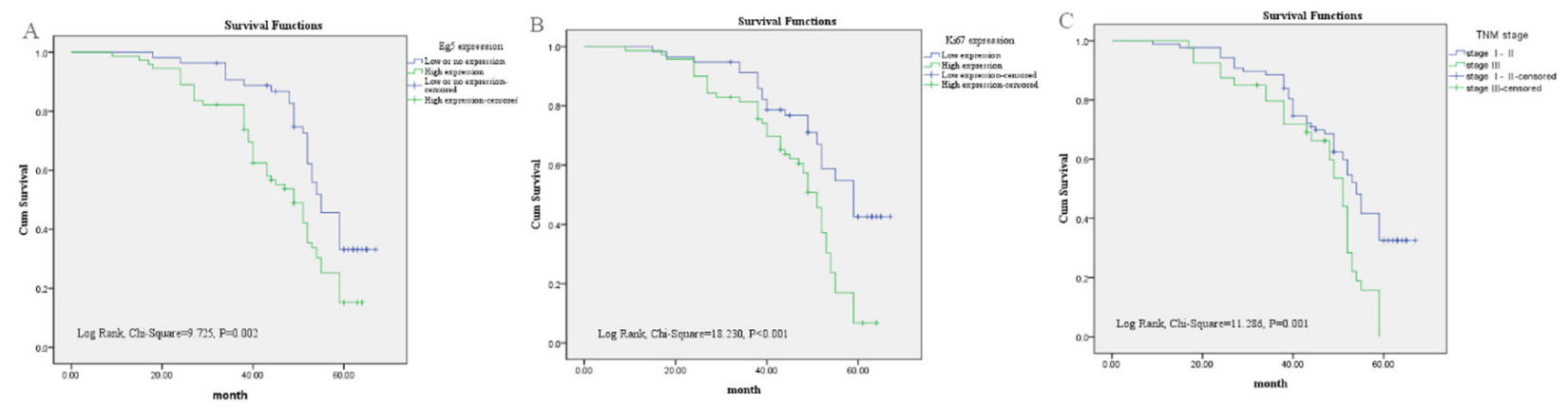

Figure 3: Survival analysis of BC patients by Kaplan-Meier method. (A) Overall survival rate in BC patients with high cytoplasmic expression of Eg5 (green line) was statistically lower than that in BC patients with low and no Eg5 expression (blue line). (B) Overall survival rate in BC patients with high Ki67 expression (green line) was statistically lower than that in BC patients with low Ki67 expression (blue line). (C) Overall survival rate in BC patients with advanced TNM stage III (green line) was statistically lower than that in BC patients with early TNM stage I-II (blue line). 
the expression of Eg5 was widely found in BC, and the results were consistent with the experimental results of Eg5 expression in several other malignant tumors. Eg5 has been implicated in tumorigenesis [25-26] because it is overexpressed and activated in leukemia; Eg5 also triggers genomic instability in transgenic mice. Hayashi et al. reported that Eg5 expression levels were proportional to the mitotic population in prostate cell lines [22]; monitoring of cells in untreated and HR22C16-A1 treated MCF-7 by using live cell confocal imaging techniques GFP-tubulin to compare the difference between the formation of microtubule spindle and cell division. Marcus et al. fund that the untreated cells, microtubules formed a bipolar spindle, then mitosis is shown after cytokinesis. The cells after HR22C16-A1 treatment, which has been found that bipolar spindle could not be formed. They indicated that Eg5 expression levels were positively associated with the mitotic index of BC [27]; Tang et al. also showed that Eg5 expression could be detected in all cases of head and neck squamous cell carcinoma, and the Eg5 expression level is correlated with cancer cell proliferative activity [28]. Consistent with previous studies, our study revealed that the Eg5 expression is correlated with malignant behaviors of $\mathrm{BC}$ development. Researchers using RNAi interference technology, Eg5 antibody neutralization and small molecule inhibitors of Eg5 can block tumor cells in metaphase of mitosis, and then lead to apoptosis. Several Eg5 inhibitors decrease cancer growth and cause tumor regression [29-31], such as Eg5 small molecule inhibitors can prevent pancreatic cancer cells from mitosis to stop pancreatic cancer cells and induce apoptosis. The molecular mechanism of Eg5 in tumorigenesis has been investigated; it is modulated by Parkin via the Hsp70-JNK-c-Jun signaling pathway [10]; the Eg5 mutation can induce drug resistance in cancer cell lines [32]; Eg5 inhibitor causes mitotic arrest in tumor cells through activation of c-Jun NH2 kinase pathway [33]. These data suggest that Eg5 represents an attractive drug target for cancer treatments [34-35]. Our study aimed to determine whether Eg5 plays a similar oncogenic role in $\mathrm{BC}$ and whether Eg5 can be used as a new biomarker for patients with $\mathrm{BC}$.

In this study, we compared the expression of Eg5 in BC tissue samples with matched non-cancerous samples. We observed that both Eg5 mRNA and protein levels were significantly higher in $\mathrm{BC}$ tumor samples than in the corresponding adjacent non-cancerous tissues. TMA-IHC analysis revealed that Eg5 expression obviously correlated with clinicopathologial parameters, including tumor grade, ER status, Ki67 status, molecular classification, $\mathrm{N}$ stage and TNM stage. Eg5 protein was predominantly localized in the cytoplasm of BC cells and all these results are consistent with previous findings in other types of cancer $[14,28]$. The results of Kaplan-Meier survival analysis show that patients with high Eg5 expression had lower survival. In addition, Cox regression analysis showed that Eg5 was an independent prognostic factor, and maybe played an important regulators involved in the development of BC.

To date, there are only a few studies reporting the prognostic significance of Eg5 in human cancers. In our study, high Eg5 protein was associated with poor overall survival for BC patients, which indicated that $\mathrm{Eg} 5$ protein level may be used as an independent marker in predicting unfavorable prognosis. Similar results were observed in two previous studies, which implied that a high Eg5 expression corresponds to a short survival time in bladder and prostate cancer patients [16-17].

Michel et al. reported a significant nuclear expression of Eg5 in prostate cancer [16]. In contrast, we mainly observed the cytoplasmic expression of Eg5 in BC tissues, and rarely detected the nuclear expression of Eg5 in $\mathrm{BC}$ tissues, These differences are probably due to the differences in tumor types and antibodies used. Future in vitro and in vivo studies that include larger number of samples are necessary to further investigate the role of Eg5 in BC tumor biology.

Taken together, we analyzed the Eg5 expression and demonstrated that $\mathrm{Eg} 5$ is involved in the $\mathrm{BC}$ development. The findings indicate that Eg5 is an independent prognostic factors of $\mathrm{BC}$ and Eg5 may be identified as a novel prognostic biomarker in $\mathrm{BC}$ patients. Relative studies concerning the potential mechanisms of Eg5 in BC and other kinds of human cancers are being performed by our research group.

\section{MATERIALS AND METHODS}

\section{Patient specimens}

20 fresh-frozen BC tissues and corresponding noncancerous tissues were collected from the Department of Pathology, the Affiliated Hospital of Nantong University. Simultaneously, a total of 127 paraffin-embedded BC tissue samples and 127 matched non-cancerous tissue samples were collected from the Department of Pathology, the Affiliated Hospital of Nantong University, between January 2007 and January 2010 to construct the tissue microarray (TMA). Diagnosis of BC was confirmed according to the latest World Health Organization criteria [2].

All 127 patients underwent mastectomy and/ or axillary dissection (radical or functional, based on clinical and surgical findings). Lymph node metastasis was confirmed by postoperative histological examination. The patients' clinical information were collected simultaneously, including patient age, tumor grade, tumor size, hormone receptor status, Her2 expression status, Ki67 status, N stage, and TNM stage. In regards to molecular classification, due to the fact that chips of genotyping are rather expensive, the majority of the professionals in Inernational Conference of Breast Cancers in St. Gallen 
in 2011 came to the conclusion that the chips pattern of genotyping could be replaced by chemical staining results of immune cells according to the ER, PR, Her2, and Ki67. According to the 2015 ST Gallen International Breast Cancer Conference [36], the cases were classified into four subtypes: Luminal (Luminal A and Luminal B), Her2-overexpression, basal-like and normal-breast-like. Triple negative breast cancer (TNBC) is the expression of $\mathrm{BC}$ when ER, PR, Her2 are all negative. But there are differences on gene expression profile and immune phenotype between TNBC and basal-like group. These two can not be exactly the same. Meanwhile, TNBC also includes part normal bresat group. Pathological stage was based on the seventh edition of the American Joint Committee on Cancer Classification (AJCC). Samples of Ki67 expression less than 14\% were considered Ki67 negative [37]. None of the patients received radiotherapy or chemotherapy before surgery. Each patient signed written informed consent for this present study. The study protocol was approved by the Ethics Committee of the Affiliated Hospital of Nantong University and all experiments were performed in accordance with approved guidelines of the Affiliated Hospital of Nantong University.

\section{Quantitative real-time polymerase chain reaction (qRT-PCR)}

20 fresh BC tissue samples and corresponding noncancerous tissue samples were used for qRT-PCR test as previously described [38]. Total RNAs were extracted using Trizol reagent (Invitrogen, Carlsbad, CA) following the manufacturer's protocols. qRT-PCR was performed using SyberGreen on an ABI 7500 thermal cycler (Applied Biosystems). The PCR procedures were as follows: UDG pre-treatment at $50{ }^{\circ} \mathrm{C}$ for $2 \mathrm{~min}, 1$ cycle; initial denaturation at $95^{\circ} \mathrm{C}$ for $10 \mathrm{~min}$; denaturation at $95^{\circ} \mathrm{C}$ for $15 \mathrm{~s}$, annealing and extension at $60^{\circ} \mathrm{C}$ for $60 \mathrm{~s}, 40$ cycles. All experiments were performed in triplicate. The primers for $\mathrm{Eg} 5$ were as follows: forward primer 5'-GAA CAA TCA TTA GCA GCA GAA-3' and reverse primer 5'-TCA GTA TAG ACA CCA CAG TTG-3'. The $\beta$-actin was used as an internal control, and the primers for $\beta$-actin were as follows: forward 5'-TAA TCT TCG CCT TAA TAC TT3', reverse 5'-AGC CTT CAT ACA TCT CAA-3'. The relative $\mathrm{Eg} 5 \mathrm{mRNA}$ expression was calculated using the $2^{-\Delta \Delta C t}$ method.

\section{Immunohistochemistry (IHC) analysis}

IHC analysis was performed as described previously [39]. Antigen retrieval was achieved by boiling under pressure in citrate buffer ( $\mathrm{pH}$ 6.0). Non-specific binding was blocked through incubation with $5 \%$ goat serum in PBS for 15 min. TMA sections were incubated with a polyclonal anti-Eg5 antibody (1:100, abcam, Cambridge, USA) and subsequently with Envision goat anti-rabbit
HRP secondary antibody (DAKO, Carpinteria, CA). The IHC analysis was performed at the same time under the same conditions. Immunostained sections were scored by two independent pathologists under blinded experimental conditions according to intensity and percentage of Eg5positive cells.

The intensity of Eg5-positive cells was scored as follows: $0,1,2$, or 3, from negative, weak, moderate, and strong intensity. The percentage of Eg5-positive cells was scored as follows: 0 for no cytoplasm expression, 1 for $1-25 \%$ positive tumor cytoplasm, 2 for $26-50 \%$ positive tumor cytoplasm, 3 for $51-75 \%$ positive tumor cytoplasm, and 4 for $76-100 \%$ positive tumor cytoplasm. The cutoff point for a statistically significant Eg5 expression score in terms of OS was set using the X-tile software program (The Rimm Lab at Yale University; http:// www.tissuearray.org/rimmlab) [40]. The multiply of the intensity and percentage scores led to as the final Eg5 staining score and was defined as follows: staining score less than 6 considered as low expression, while staining score of 7 or more was considered as high expression.

\section{Statistical analysis}

The mRNA expression of Eg5 in fresh BC tissues and corresponding non-cancerous tissues was calculated by the Wilcoxon signed-rank nonparametric test. Pearson's $\chi 2$ was conducted to examine the correlation between Eg5 protein expression and clinicopathological parameters. Kaplan-Meier and log-rank test were performed to calculate the survival curves. Factors that of prognostic significance in the univariate analysis were further analyzed using a multivariate Cox regression model. For all tests, $p$-values less than 0.05 were considered statistically significant. All statistical works were analyzed using STATA Version 12.0 software (Stata Corporation, College Station, TX).

\section{ACKOWLEDGMENTS}

This study was supported by the clinic master grant (2014) from Medical Research Program of Nantong University, Jiangsu, China; Technology innovation and demonstration project of Nantong science(HS 2014047).

\section{CONFLICTS OF INTEREST}

The authors do not have any conflicts of interest.

\section{REFERENCES}

1. Pang B, Cheng S, Sun SP, An C, Liu ZY, Feng X, Liu GJ. Prognostic role of pik3ca mutations and their association with hormone receptor expression in breast cancer: a metaanalysis. Sci Rep. 2014; 4:6255. https://doi.org/10.1038/ srep06255. 
2. Lin H, Huang JF, Qiu JR, Zhang HL, Tang XJ, Li H, Wang CJ, Wang ZC, Feng ZQ, Zhu J. Significantly upregulated tacstd2 and cyclin d1 correlate with poor prognosis of invasive ductal breast cancer. Exp Mol Pathol. 2013; 94:73-78.

3. Xu X, Tang X, Lu M, Tang Q, Zhang H, Zhu H, Xu N, Zhang D, Xiong L, Mao Y, Zhu J. Overexpression of MAGE-A9 predicts unfavorable outcome in breast cancer. Exp Mol Pathol. 2014; 97:579-584.

4. Li XY, Luo QF, Li J, Wei CK, Kong XJ, Zhang JF, Fang L. Clinical significance of nob1 expression in breast infiltrating ductal carcinoma. Int J Clin Exp Pathol. 2013; 6:2137-2144.

5. DeNardo DG, Brennan DJ, Rexhepaj E, Ruffell B, Shiao SL, Madden SF, Gallagher WM, Wadhwani N, Keil SD, Junaid SA, Rugo HS, Hwang ES, Jirström K, et al. Leukocyte complexity predicts breast cancer survival and functionally regulates response to chemotherapy. Cancer Discov. 2011; 1: 54-67.

6. Lin H, Zhang H, Wang J, Lu M, Zheng F, Wang C, Tang $\mathrm{X}, \mathrm{Xu} \mathrm{N}$, Chen R, Zhang D, Zhao P, Zhu J, Mao Y, Feng Z. A novel human fab antibody for trop2 inhibits breast cancer growth in vitro and in vivo. Int J Cancer. 2014; 134:1239-1249.

7. Yang P, Du CW, Kwan M, Liang SX, Zhang GJ. The impact of p53 in predicting clinical outcome of breast cancer patients with visceral metastasis. Sci Rep. 2013; 3:246.

8. Kapitein LC, Peterman EJ, Kwok BH, Kim JH, Kapoor TM, Schmidt CF. The bipolar mitotic kinesin eg5 moves on both microtubules that it crosslinks. Nature. 2005; 435:114-118.

9. Valentine MT, Gilbert SP. To step or not to step? How biochemistry and mechanics influence processivity in kinesin and eg5. Curr Opin Cell Biol. 2007; 19:75-81.

10. Liu M, Aneja R, Sun X, Xie S, Wang H, Wu X, Dong JT, Li M, Joshi HC, Zhou J. Parkin regulates eg5 expression by hsp70 ubiquitination-dependent inactivation of c-jun nh2terminal kinase. J Biol Chem. 2008; 283:35783-35788.

11. Zhang $\mathrm{Y}, \mathrm{Xu}$ W. Progress on kinesin spindle protein inhibitors as anti-cancer agents. 2008; 8:698-704.

12. Gable A, Qiu M, Titus J, Balchand S, Ferenz NP, Ma N, Collins ES, Fagerstrom C, Ross JL, Yang G, Wadsworth P. Dynamic reorganization of Eg5 in the mammalian spindle throughout mitosis requires dyneinand TPX2. Mol Biol Cell. 2012; 23:1254-1266.

13. Hansen GM, Justice MJ. Activation of hex and meg5 by retroviral insertion may contribute to mouse b-cell leukemia. Oncogene. 1999; 18:6531-6539.

14. Saijo T, Ishii G, Ochiai A, Yoh K, Goto K, Nagai K, Kato H, Nishiwaki Y, Saijo N. Eg5 expression is closely correlated with the response of advanced non-small cell lung cancer to antimitotic agents combined with platinum chemotherapy. Lung Cancer. 2006; 54:217-225.

15. Ding S, Lu J, Ding K, Bi D, Niu Z, Cao Q, Zhang J, Ding S. The expression of Eg5 predicts a poor outcome for patients with renal cell carcinoma. Ted Oncol. 2013; 30:476.

16. Wissing MD, De Morrée ES, Dezentjé VO, Buijs JT, De Krijger RR, Smit VT, Van Weerden WM, Gelderblom H, van der Pluijm G. Nuclear eg5 (kinesin spindle protein) expression predicts docetaxel response and prostate cancer aggressiveness. Oncotarget. 2014; 5:7357-7367. https://doi. org/10.18632/oncotarget.1985.

17. Ding S, Xing N, Lu J, Zhang H, Nishizawa K, Liu S, Yuan $\mathrm{X}$, Qin Y, Liu Y, Ogawa O, Nishiyama H. Overexpression of eg5 predicts unfavorable prognosis in non-muscle invasive bladder urothelial carcinoma. Int J Urol. 2011; 18:432-438.

18. Lu M, Zhu H, Wang X, Zhang D, Xiong L, Xu L, You Y. The prognostic role of Eg5 expression in laryngeal squamous cell carcinoma. Pathology. 2016; 48:214-218.

19. Liu L, Liu X, Mare M, Dumont AS, Zhang H, Yan D, Xiong Z. Overexpression of Eg5 correlates with high grade astrocytic neoplasm. J Neurrooncol. 2016; 126:77-80.

20. Sun XD, Shi XJ, Sun XO, Luo YG, Wu XJ, Yao CF, Yu HY, Li DW, Liu M, Zhou J. Dimethylenastron suppresses human pancreatic cancer cell migration and invasion in vitro via allosteric inhibition of mitotic kinesin Eg5. Acta Pharmacol Sin. 2011; 10:1-6.

21. Planas-Silva MD, Filatova IS. Estrogen-dependent regulation of Eg5 in breast cancer cells. Anticancer Drugs. 2007; 18:773-779.

22. Hayashi N, Koller E, Fazli L, Gleave ME. Effects of eg5 knockdown on human prostate cancer xenograft growth and chemosensitivity. Prostate. 2008; 68:1283-1295.

23. Carter BZ, Mak DH, Shi Y, Schober WD, Wang RY, Konopleva M, Koller E, Dean NM, Andreeff M. Regulation and targeting of eg5, a mitotic motor protein in blast crisis cml: overcoming imatinib resistance. Cell Cycle. 2006; 5:2223-2239.

24. Castillo A, Morse HC 3rd, Godfrey VL, Naeem R, Justice MJ. Overexpression of eg5 causes genomic instability and tumor formation in mice. Cancer Res. 2007; 67:10138-10147.

25. Nowicki MO, Pawlowski P, Fischer T, Hess G, Pawlowski T, Skorski T. Chronic myelogenous leukemia molecular signature. Oncogene. 2003; 22:3952-3963.

26. Kaiser A, Brembeck FH, Nicke B, Wiedenmann B, Riecken EO, Rosewicz S. All-trans-retinoic acid-mediated growth inhibition involves inhibition of human kinesin-related protein hseg5. J Biol Chem. 1999; 27:18925-18931.

27. Marcus A, Peters U, Thomas SL, Garrett S, Zelnak A, Kapoor TM, Giannakakou P. Mitotic kinesin inhibitors induce mitotic arrest and cell death in taxolresistant and-sensitive cancer cells. J Biol Chem. 2005; 280:11569-11577.

28. Tang PA, Siu LL, Chen EX, Hotte SJ, Chia S, Schwarz JK, Pond GR, Johnson C, Colevas AD, Synold TW, Vasist 
LS, Winquist E. Phase II study of ispinesib in recurrent or metastatic squamous cell carcinoma of the head and neck. Invest New Drugs. 2008; 26:257-264.

29. Exertier P, Javerzat S, Wang B, Franco M, Herbert J, Platonova N, Winandy M, Pujol N, Nivelles O, Ormenese $\mathrm{S}$, Godard V, Becker J, Bicknell R, et al. Impaired angiogenesis and tumor development by inhibition of the mitotic kinesin eg5. Oncotarget. 2013; 4:2302-2316. https:// doi.org/10.18632/oncotarget.1490.

30. Marquis L, Tran M, Choi W, Lee IL, Huszar D, SiefkerRadtke A, Dinney C, McConkey DJ. P63 expression correlates with sensitivity to the eg5 inhibitor zd4877 in bladder cancer cells. Cancer Biol Ther. 2012; 13:477-486.

31. Yang L, Jiang C, Liu F, You QD, Wu WT. Cloning, enzyme characterization of recombinant human eg5 and the development of a new inhibitor. Biol Pharm Bulletin. 2008; 31:1397-1402.

32. Tcherniuk S, van Lis R, Kozielski F, Skoufias DA. Mutations in the human kinesin eg5 that confer resistance to monastrol and s-trityl-1-cysteine in tumor derived cell lines. Biochem Pharmacol. 2010; 79:864-872.

33. Shi J, Orth JD, Mitchison T. Cell type variation in responses to antimitotic drugs that target microtubules and kinesin-5. Cancer Res. 2008; 68:3269-3276.

34. DeBonis S, Skoufias DA, Lebeau L, Lopez R, Robin G, Margolis RL, Wade RH, Kozielski F. In vitro screening for inhibitors of the human mitotic kinesin eg5 with antimitotic and antitumor activities. Mol Cancer Ther. 2004; 3:1079-1090.
35. Sakowicz R, Finer JT, Beraud C, Crompton A, Lewis E, Fritsch A, Lee Y, Mak J, Moody R, Turincio R, Chabala JC, Gonzales P, Roth S, et al. Antitumor activity of a kinesin inhibitor. Cancer Res. 2004; 64:3276-3280.

36. Esposoto A, Criscitiello C, Cruigliano G. Highlights from the 14(th) St Gallen International Breast Cancer Conference 2015 in Vienna: dealing withclassification, prognostication, and prediction refinement to personalize the treatment of patients with early breastcancer. Ecancermedicalscience. 2015; 9:518.

37. Cheang MC, Chia SK, Voduc D, Gao D, Leung S, Snider J, Watson M, Davies S, Bernard PS, Parker JS, Perou CM, Ellis MJ, Nielsen TO. Ki67 index, HER2 status, and prognosis of patients with luminal B breast cancer. J Natl Cancer Inst. 2009; 101:736-750.

38. Huang H, Zhai X, Zhu H, Wang W, Zhang S, Wu L, Zhang J. Upregulation of atoh1 correlates with favorable survival in gastrointestinal stromal tumor. Int J Clin Exp Pathol. 2014; 7:7123-7130.

39. Ni S, Xu L, Huang J, Feng J, Zhu H, Wang G, Wang X. Increased zo-1 expression predicts valuable prognosis in non-small cell lung cancer. Int J Clin Exp Pathol. 2013; 6:2887-2895.

40. Huang J, Mei H, Tang Z, Li J, Zhang X, Lu Y, Huang F, Jin Q, Wang Z. Triple-amiRNA VEGFRs inhibition in pancreatic cancer improves the efficacy of chemotherapy through EMT regulation. J Control Release. 2017; 245:1-14. 